\title{
His bundle electrogram in patients with acute myocardial infarction complicated by atrioventricular or intraventricular conduction disturbances
}

\author{
Richard Harper, David Hunt, Jitu Vohra, Thomas Peter, and Graeme Sloman \\ From the Cardiology Department, Royal Melbourne Hospital, Victoria, Australia
}

Seventy-two patients with acute myocardial infarction complicated by atrioventricular or bundle-branch block or a combination of both had His bundle electrogram studies performed during their stay in the coronary care unit. In 19 of the 72 patients a repeat His bundle electrogram was performed before discharge from hospital. These studies demonstrated that 30 of the 32 patients with atrioventricular block and narrow QRS complexes had a block above the origin of the His spike (proximal block). Eleven patients in this group had repeat His bundle electrograms performed before discharge and in 3 patients there was evidence of residual atrioventricular nodal dysfunction. Both the hospital and follow-up mortality in this group was low and there was no evidence to suggest that permanent pacing would benefit these patients.

Of the 18 patients with bundle-branch block and a normal PR interval, 9 had prolongation of the HV interval, but there was no difference in mortality in patients with normal or prolonged $H V$ intervals. Twentytwo patients with bundle-branch block also developed atrioventricular block. In 5 of these patients the site of the AV block was proximal and in 14 it was distal, while 3 patients had both proximal and distal block. The hospital mortality in those patients who progressed to second-or third-degree atrioventricular block was considerably higher than in those patients who remained in first-degree atrioventricular block.

In recent years the His bundle electrogram has been increasingly used in the assessment of intracardiac conduction (Damato et al., 1969; Hunt et al., 1974; Narula et al., 1970; Dreifus et al., I97I) and in the analysis of cardiac arrhythmias (Castellanos, Castillo, and Agha, 1971; Haft, I973). There are few reports, however, concerning the implications of His bundle electrogram findings in the setting of acute myocardial infarction (Rosen et al., 1970; Hunt et al., 1973; Arcebal et al., 1970; Narula and Javier, 1970; Lichstein et al., 1973). This paper describes our experience with the His bundle electrogram in patients with intraventricular and/or atrioventricular conduction defects in the early phase of acute myocardial infarction. An attempt has been made to correlate the findings with subsequent short- and long-term prognosis and, in particular, to evaluate the role of the His bundle electrogram in determining which patients require temporary or permanent cardiac pacing.

Received 23 December 1974.

\section{Subjects and methods}

Seventy-two patients admitted to the Royal Melbourne Hospital Coronary Care Unit over a period of two years with acute myocardial infarction (WHO Class I) had His bundle electrograms recorded during the acute phase of their illness. The indications for the study in these patients were the presence of atrioventricular or bundle-branch block or a combination of both. Informed consent was obtained from all patients before the study. The His bundle electrogram studies were performed under local anaesthesia using a tripolar No. 7 USCI catheter introduced percutaneously from the right groin. The catheter was positioned across the tricuspid valve under fluoroscopic control and manipulated to achieve the optimal recording of the His deflection (Scherlag et al., 1969). The signal was passed through a battery box to two phonocardiographic preamplifiers and an electrocardiographic preamplifier. The signal was passed through a filter system with a range of 40-500 Hz. Two surface electrocardiographic leads were chosen to show clearly the onset of ventricular activity. Atrial pacing was not performed at the initial study. The signals were observed on a Sanborn 764 eight-channel oscilloscope and recorded on light sensitive paper at $500 \mathrm{~m} / \mathrm{s}$ on a Sanborn 560 recorder. After recording the 
His bundle electrogram in patients with atrioventricular block a bipolar pacing catheter was positioned at the apex of the right ventricle using the same femoral vein, and this catheter was left in situ and connected to an external pacemaker set in the demand mode. Shortly before discharge from hospital a repeat His bundle electrogram was recorded, where possible, by manipulating the pacing wire during its removal.

Measurements were made of the AH interval (from the onset of atrial activity on the His bundle electrogram to the first rapid deflection of the $\mathrm{H}$ spike) and the HV interval (from the first rapid deflection of the $\mathrm{H}$ spike to the earliest evidence of ventricular activity as seen on any of the surface or intracardiac recordings). At least five beats were measured and averaged. We took the upper limit of normal for the AH interval to be $120 \mathrm{~ms}$ (Scherlag et al., 1969) (providing the heart rate was less than 100 per minute), and $55 \mathrm{~ms}$ was taken to be the upper limit of normal for the HV interval (Narula and Samet, 1970). None of our patients was receiving drugs affecting atrioventricular conduction at the time of study.

The patients were continuously monitored in the coronary care unit for an average of three days and then discharged to a hospital ward. In 19 patients a repeat His bundle electrogram, with atrial pacing to a rate of roo beats a minute, was performed during the convalescent stage (usually about ro to 14 days after the acute myocardial infarction). All were followed for a minimum of 3 months after discharge from the hospital. The mean follow-up period was 9 months.

For the purpose of analysis the patients were divided into three groups as shown in the Table.

\section{Group I: atrioventricular block only}

This group consisted of 32 patients with atrioventricular block of greater than first-degree in the absence of any intraventricular conduction defect. Thus, these patients had normal width QRS complexes even during high degree atrioventricular block.

\section{Group 2: bundle-branch block only}

This group consisted of 18 patients in sinus rhythm and a normal PR interval, with complete left bundle-branch block or right bundle-branch block, with or without a left anterior or posterior hemiblock (Rosenbaum, 1970). The bundle-branch block was present either on admission or developed during the course of the coronary care stay.

TABLE

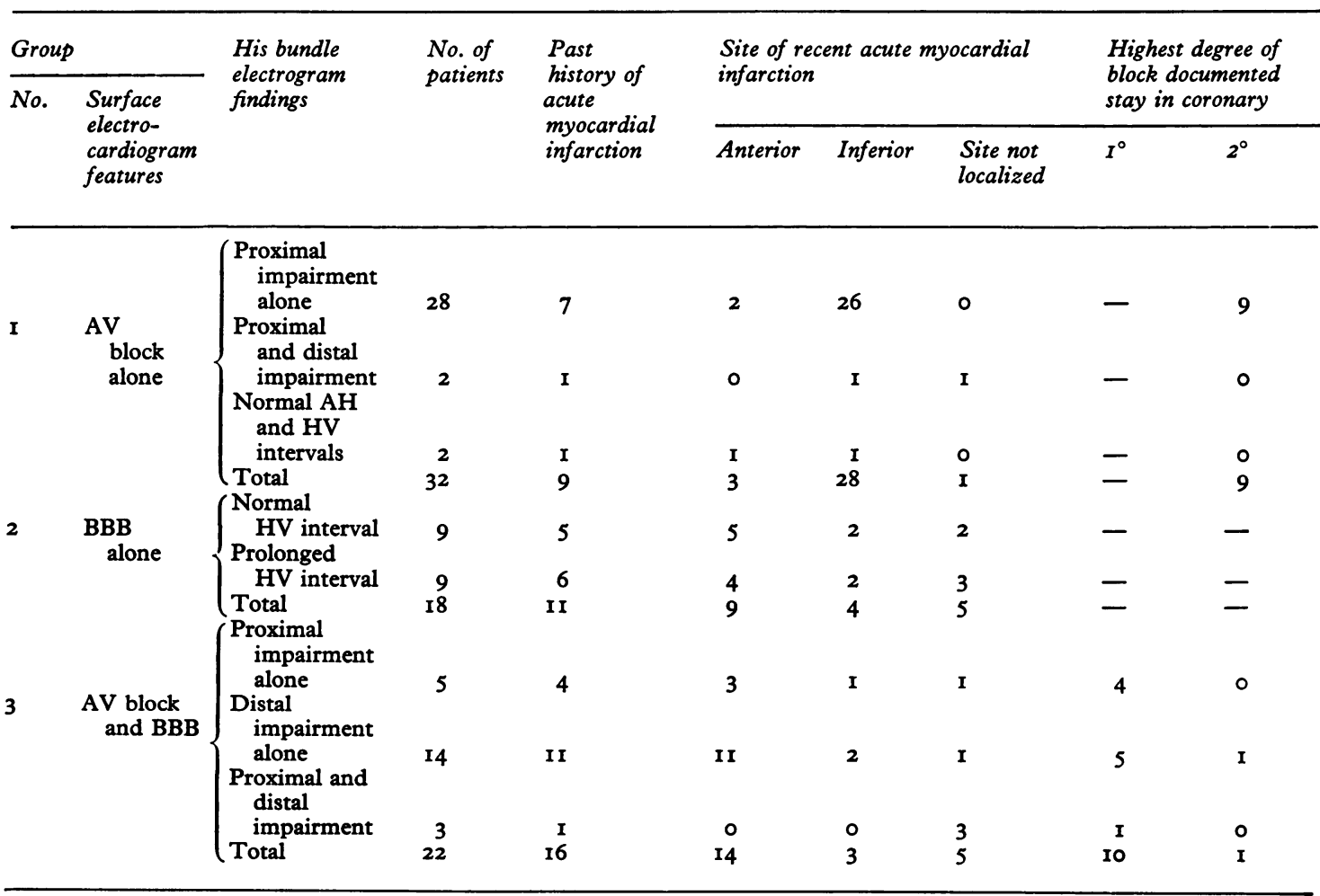

* I patient lost to follow-up.

AV, atrioventricular; BBB, bundle-branch block; RBBB, right bundle-branch block; LBBB, left bundle-branch block. 


\section{Group 3: atrioventricular block plus bundle- branch block}

This group consisted of 22 patients with either a complete left or right bundle-branch block plus an episode of atrioventricular block of any degree occurring during the course of their acute myocardial infarction.

The His bundle electrogram was not always obtained when the patients were in their highest degree of block. Thus, several patients who had had episodes of thirddegree heart block had reverted to first-degree atrioventricular block at the time of their study.

On the basis of the His bundle electrogram findings, impairment of proximal conduction (atrioventricular nodal dysfunction) was said to be present if one or more of the following criteria were satisfied.

i) The patient had a second- or third-degree atrioventricular block of the proximal type with each QRS complex preceded by a His spike with a fixed HV interval.

ii) There was prolongation of the $\mathrm{AH}$ interval above I20 ms during sinus rhythm.

iii) The patient developed a proximal atrioventricular nodal block at atrial pacing rates of less than IIO beats per minute.
Impairment of distal conduction was considered to be present if there was prolongation of the $\mathrm{HV}$ interval or if in the presence of second- or third-degree atrioventricular block a His spike was recorded following a nonconducted $\mathrm{A}$ wave.

\section{Results}

The results are summarized in the Table.

\section{Group I: atrioventricular block only}

The mean age of the patients in this group was 60 years. Thirty of the 32 patients had evidence of atrioventricular nodal dysfunction at the time of study; 9 were in complete atrioventricular block of the proximal type and the mean ventricular rate of the 9 patients was 6I beats per minute. Seven patients were in second-degree atrioventricular block of the proximal type and the remaining 14 patients were in first-degree atrioventricular block with a prolonged $\mathrm{AH}$ interval though all of them had had a higher degree of atrioventricular block before the study. The remaining 2 patients, who

\begin{tabular}{|c|c|c|c|c|c|c|c|c|}
\hline \multirow{2}{*}{$\begin{array}{l}\text { atrioventricular } \\
\text { during } \\
\text { care unit } \\
3^{\circ}\end{array}$} & \multicolumn{5}{|c|}{ Bundle-branch block } & \multicolumn{3}{|l|}{ Mortality } \\
\hline & $\begin{array}{l}R B B B \\
\text { (normal } \\
\text { axis) }\end{array}$ & $\begin{array}{l}R B B B \\
\text { (left axis } \\
\text { deviation) }\end{array}$ & $\begin{array}{l}R B B B \\
\text { (right axis } \\
\text { deviation) }\end{array}$ & $L B B B$ & $\begin{array}{l}R B B B \\
\text { plus } \\
L B B B\end{array}$ & $\begin{array}{l}\text { Hospital } \\
\text { mortality }\end{array}$ & $\begin{array}{l}\text { Follow-up } \\
\text { mortality }\end{array}$ & $\begin{array}{l}\text { Total } \\
\text { mortality }\end{array}$ \\
\hline
\end{tabular}

\begin{tabular}{|c|c|c|c|c|c|c|c|c|}
\hline 19 & - & - & - & - & - & 3 & I & 4 \\
\hline 2 & - & - & - & - & - & I & 0 & I \\
\hline 2 & - & - & - & - & - & 0 & 0 & 0 \\
\hline 23 & - & - & - & - & - & 4 & $\mathbf{I}$ & 5 \\
\hline- & 5 & $\mathbf{I}$ & 2 & I & 0 & 0 & I & I \\
\hline- & 4 & 0 & I & 3 & I & 0 & $I^{\star}$ & I \\
\hline- & 9 & $\mathbf{I}$ & 3 & 4 & I & 0 & $2^{\star}$ & 2 \\
\hline I & 2 & I & 0 & 2 & 0 & I & I & 2 \\
\hline 8 & 4 & 3 & 0 & 0 & 7 & 10 & 0 & 10 \\
\hline 2 & 2 & $\mathbf{I}$ & 0 & 0 & 0 & 0 & 0 & 0 \\
\hline II & 8 & 5 & 0 & 2 & 7 & II & $\mathbf{I}$ & 12 \\
\hline
\end{tabular}


had both had transient episodes of complete heart block, had reverted to sinus rhythm at the time of study and both had normal AH and HV intervals. Of the 9 patients with complete heart block at the time of study, 2 also had prolonged HV intervals ( $60 \mathrm{~ms}$ and $65 \mathrm{~ms}$, respectively). In the other 30 patients the HV intervals were normal. None of the patients had a block below the His spike.

Four of the 32 patients died in hospital and I patient died during the 3-month follow-up period. All the 28 hospital survivors had returned to sinus rhythm at the time of discharge. Eleven patients had a repeat His bundle electrogram study just before discharge, and in 8 patients there was no evidence of any atrioventricular nodal dysfunction while in 3 patients residual atrioventricular nodal dysfunction was detected by atrial pacing. None of the II patients was receiving digitalis at the time of the repeat study. The HV interval of the initial and later study was remarkably constant and the variation did not exceed $5 \mathrm{~ms}$ in any patient (Fig.).

\section{Group 2: bundle-branch block only}

The mean age of patients in this group was 62 years. The His bundle electrogram showed that 9 of the 18 patients had a prolonged $\mathrm{HV}$ interval of greater than $55 \mathrm{~ms}$. None of the 18 patients died in hospital but 2 patients died within three months of discharge from hospital and I patient was lost to follow-up. Of the 2 patients who died, one had had a prolonged $\mathrm{HV}$ interval while in the other it was normal. Three of the 18 patients had repeat His bundle electrograms and the variation in the $\mathrm{HV}$ intervals between the initial and the repeat study was within $10 \mathrm{~ms}$ (Fig.).

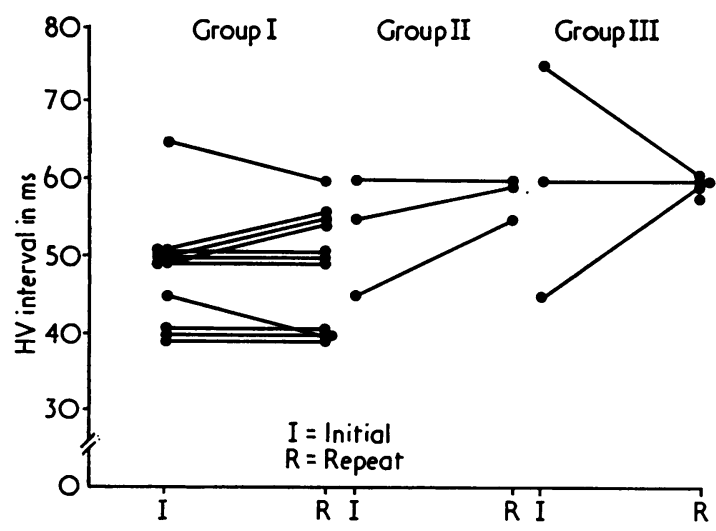

FIG. Initial and repeat measurements of $H V$ intervals in the three groups (see text).

\section{Group 3: atrioventricular block plus bundle-} branch block

The mean age of the 22 patients in this group was 67 years. The His bundle electrogram showed that the atrioventricular block was caused by a proximal block in 5 cases, a distal block in 14 cases, and both distal and proximal block in 3 patients. One of the 5 patients with proximal block died in hospital while Io of the 14 patients with distal block died in hospital. Twelve of the 22 patients developed second-degree or third-degree atrioventricular block, and the other Io patients had first-degree atrioventricular block only. Of the ro patients with first-degree atrioventricular block alone, 4 patients had a prolonged $\mathrm{AH}$ interval, with a normal $\mathrm{HV}$ interval, and 5 patients had a prolonged $\mathrm{HV}$ interval with a normal $\mathrm{AH}$ interval, and I patient had both a prolonged $\mathrm{AH}$ and $\mathrm{HV}$ interval. Two of the Io patients died in hospital and I further patient died during the 3-month follow-up period. Of the 12 patients who progressed to second- or third-degree atrioventricular block, one had a proximal block alone, 2 patients had evidence of both proximal and distal block, and 9 patients had distal block alone. Nine of the 12 patients died in hospital despite temporary cardiac pacing: these deaths were all caused by myocardial failure. The 3 patients who survived to leave hospital had all returned to sinus rhythm with a normal PR interval and all 3 were alive at the time of follow-up.

Five of the 12 patients in this group who survived to leave hospital had repeat His bundle electrogram studies. Two of the 5 patients had a distal block at the time of the initial study and thus the HV interval could not be obtained. In 2 of the remaining 3 patients the variation in the HV interval between the initial and the repeat study was greater than $15 \mathrm{~ms}$ and in the other patient the variation was less than $5 \mathrm{~ms}$ (Fig.).

\section{Discussion}

Patients who develop atrioventricular (Watson and Goldberg, 1971) and intraventricular (Hunt and Sloman, 1969; Norris and Croxson, 1970) conduction disturbances during the course of acute myocardial infarction have a high hospital mortality, and in those patients who survive to leave hospital the subsequent mortality over the next 12 months is also high (Denborough et al., 1968). Most evidence suggests that the high mortality in the acute phase is caused predominantly by mechanical failure associated with a large infarction, and that temporary cardiac pacing does little to reduce this mortality (Sutton, Chatterjee, and Leatham, 1968; Lassers and Julian, 1968; Godman, Lassers, and 
Julian, I970). Of those patients who survive to leave hospital, however, there is a high incidence of sudden death (Atkins et al., I973; Lichstein et al., 1973; Waugh et al., 1973) possibly because of cardiac asystole (Waugh et al., 1973). Several authors have suggested that some of these deaths may be prevented by permanent cardiac pacing (Atkins et al., 1973; Lichstein et al., 1973; Waugh et al., 1973). It, therefore, seems important to identify the patients at highest risk from this complication. The technique of His bundle electrography has enabled atrioventricular conduction disturbances to be localized to the atrioventricular node (proximal block) or to the distal conducting system (distal block). It also provides an assessment of conduction of the remaining fascicle or fascicles in patients with complete bundle-branch block.

Complete heart block complicating acute myocardial infarction usually occurs in one of two electrocardiographic patterns. Patients with complete atrioventricular block and narrow QRS complexes generally have atrioventricular nodal ischaemia. In the majority of cases this is consequent to an inferior infarction as demonstrated in our series. Patients with complete atrioventricular block and wide QRS complexes generally have bilateral bundle-branch damage caused by massive septal involvement (Rosen et al., 1970). In our study 30 out of $\mathbf{3 2}$ patients in group I had evidence of atrioventricular nodal dysfunction at the time of the His bundle electrogram. The remaining 2 patients were in sinus rhythm with normal PR interval (normal AH and $H V$ interval) and it is presumed that the heart block was caused by transient nodal atrioventricular nodal ischaemia. Though 2 patients had slightly prolonged $\mathrm{HV}$ intervals in addition to complete atrioventricular block of proximal type, it is certain that impairment of distal conduction did not contribute to the heart block. It is possible that intra-Hisian block could cause complete atrioventricular block with narrow complexes (Narula et al., 1970; Rosen et al., 1970; Gupta, Lichstein, and Chadda, 1973), but this phenomenon was not observed in any of our patients. Thus, in this group the His bundle electrogram offered no advantage over conventional electrocardiographic criteria in diagnosing the site of heart block. The mortality in this group was relatively low $(13 \%)$, and the role of temporary pacing in reduction of mortality is difficult to assess, as these patients generally have a stable nodal pacemaker with an adequate ventricular rate (Norris, 1969). Furthermore, all patients who survived to leave hospital had returned to sinus rhythm with a normal PR interval though 3 of the II patients who were studied had evidence of residual atrioventricular nodal dysfunction. The repeat His bundle electrogram studies in this group of patients (group I), in whom the septum was not involved in the acute infarction, also showed that the $\mathrm{HV}$ interval was constant (within $5 \mathrm{~ms}$ ) in all cases. There was only I death in the follow-up period, and thus it seems unlikely that this group of patients would benefit from long-term cardiac pacing.

In patients with complete bundle-branch block and a normal PR interval (group 2) occurring during the course of acute myocardial infarction, 50 per cent had prolongation of the HV interval. This could not have been detected by conventional electrocardiographic criteria, and thus the His bundle electrogram remains the only means of further analysing atrioventricular conduction. A prolonged $\mathrm{HV}$ in this context indicates disease either in the His bundle or in the remaining bundlebranch. The documentation of trifascicular disease as a common antecedent to complete heart block (Godman, Alpert, and Julian, 197I) lends support to the view that in these patients sudden death caused by cardiac asystole might be prevented by permanent demand pacing. The low mortality in our patients in this group suggests that a prospective study involving large numbers of patients will be necessary before any conclusions can be drawn as to whether or not this view is valid.

In patients who develop atrioventricular block in association with a complete bundle-branch block, the His bundle electrogram is the only means of determining whether the atrioventricular block is caused by distal or proximal disease. A distal block in this setting indicates bilateral bundle-branch block, with a high probability of developing complete heart block and a high acute mortality (Godman et al., 1971). Thus, on these grounds, one would expect patients with proximal block to do better than patients with distal block and this was so in our series ( $\mathrm{I}$ out of 5 patients with proximal block and ro out of 14 patients with distal block died in hospital).

In our series proximal block was more common in patients with only first-degree heart block ( 4 out of 10) than in those progressing to higher degrees of block (I out of 12). As expected patients with complete bundle-branch block who developed secondor third-degree atrioventricular block had a high early mortality, and only 3 of the 12 patients survived to leave hospital. Surprisingly none of the 3 died during the follow-up period (all these 3 patients have been followed for over I2 months). Thus, though these patients may have benefited from temporary cardiac pacing in the acute stage, we have no evidence to suggest that permanent pacing is of value in reducing the mortality. Further- 
more, in 2 of the patients in group I who had repeat His bundle electrogram studies there was a reduction in the HV interval, suggesting that acute ischaemic damage to the distal conducting system may be reversible, and for this reason we believe that repeat His bundle electrogram studies are useful in providing a more accurate assessment of distal conduction at the time of discharge from hospital.

In conclusion, we consider that His bundle electrogram studies provide additional information about intracardiac conduction in patients with acute myocardial infarction and wide QRS complexes with or without atrioventricular block. This information, however, did not affect the acute management of these patients and whether it will be of value in selecting patients who will benefit from permanent cardiac pacing will only be determined by long-term prospective studies involving large numbers of patients. In patients with atrioventricular block and narrow QRS complexes, the His bundle electrogram does not provide any additional information as to the site of block that could not have been obtained from the surface electrocardiogram.

\section{References}

Arcebal, A. G., Machado, H., Lemberg, L., Castillo, C. A., and Castellanos, A. (1970). His bundle electrograms in type II (Mobitz) block occurring during acute myocardial infarction (abstract). Circulation, 45 and 46, Suppl. II, 125.

Atkins, J. M., Leshin, S. J., Blomqvist, G., and Mullins, C. B. (1973). Pacing for ventricular conduction blocks and sudden death in acute myocardial infarction. New England Fournal of Medicine, 288, $28 \mathrm{r}$.

Castellanos, A., Castillo, C. A., and Agha, A. S. (I97I). Contribution of His bundle recordings to the understanding of clinical arrhythmias. American fournal of Cardiology, 28, 499.

Damato, A. N., Lau, S. H., Helfant, R., Stein, E., Patton, R. D., Scherlag, B. J., and Berkowitz, W. D. (I969). A study of heart block in man using His bundle recordings. Circulation, 39, 297.

Denborough, M. A., Lovell, R. R. H., Nestel, P. J., and Goble, A. J. (1968). Arrhythmias and late sudden death after myocardial infarction. Lancet, $r, 386$.

Dreifus, L. S., Watanabe, Y., Haiat, R., and Kimbiris, D. (1971). Atrioventricular block. American fournal of Cardiology, 28, 371 .

Godman, M. J., Alpert, B. A., and Julian, D. G. (1971). Bilateral bundle-branch block complicating acute myocardial infarction. Lancet, 2, 345.

Godman, M. J., Lassers, B. W., and Julian, D. G. (1970). Complete bundle-branch block complicating acute myocardial infarction. New England fournal of Medicine, 282, 237.

Gupta, P. K., Lichstein, E., and Chadda, K. (1973). Electro- physiological features of complete AV block within the His bundle. British Heart fournal, 35, 610.

Haft, J. I. (1973). The His bundle electrogram. Circulation $47,897$.

Hunt, D., Lie, J. T., Vohra, J., and Sloman, G. (1974). The His bundle electrogram in impaired atrioventricular conduction. Advances in Cardiology, 12, 279.

Hunt, D., Lie, J. T., Vohra, J., and Sloman, G. (1973). Histopathology of heart block complicating acute myocardial infarction. Circulation, 48, 1252.

Hunt, D., and Sloman, G. (1969). Bundle-branch block in acute myocardial infarction. British Medical fournal, $\mathbf{I}$, 85 .

Lassers, B. W., and Julian, D. G. (1968). Artificial pacing in management of complete heart block complicating acute myocardial infarction. British Medical fournal, 2, 142.

Lichstein, E., Gupta, P. K., Chadda, K. D., Liu, H. M., and Sayeed, M. (1973). Findings of prognostic value in patients with incomplete bilateral bundle-branch block complicating acute myocardial infarction. American fournal of Cardiology, 32, 913.

Narula, O. S., and Javier, R. P. (1970). Sequelae of A-V block in acute myocardial infarction (abstract). Circulation, 45 and 46, Suppl. II, 197.

Narula, O. S., and Samet, P. (1970). Wenkebach and Mobitz type II A-V block due to block within the His bundle and bundle branches. Circulation, 41, 947.

Narula, O. S., Scherlag, B. J., Javier, R. P., Hildner, F. J., and Samet, P. (1970). Analysis of the A-V conduction defect in complete heart block utilizing His bundle electrograms. Circulation, 4I, 437.

Norris, R. M. (1969). Heart block in posterior and anterior myocardial infarction. British Heart fournal, 31, 352.

Norris, R. M., and Croxson, M. S. (I970). Bundle branch block in acute myocardial infarction. American Heart Fournal, 79, 728.

Rosen, K. M., Loeb, H. S., Chuquimia, R., Sinno, M. Z., Rahimtoola, S. H., and Gunnar, R. M. (1970). Site of heart block in acute myocardial infarction. Circulation, 42, 925.

Rosenbaum, M. B. (1970). The hemiblocks, diagnostic criteria and clinical significance. Modern Concepts of Cardiovascular Disease, 39, I41.

Scherlag, B. J., Lau, S. H., Helfant, R. H., Berkowitz, W. D. Stein, E., and Damato, A. N. (1969). Catheter technique for recording His bundle activity in man. Circulation, 39, 13.

Sutton, R., Chatterjee, K., and Leatham, A. (1968). Heartblock following acute myocardial infarction. Treatment with demand and fixed-rate pacemakers. Lancet, 2, 645 .

Watson, C. C., and Goldberg, M. J. (I97I). Evaluation of pacing for heart block in myocardial infarction. British Heart fournal, 33, 120.

Waugh, R. A., Wagner, G. S., Haney, T. L., Rosati, R. A., and Morris, J. J. (I973). Immediate and remote prognostic significance of fascicular block during acute myocardial infarction. Circulation, 47, 765 .

Requests for reprints to Dr. David Hunt, Cardiology Department, The Royal Melbourne Hospital, Victoria 3050, Australia. 